\title{
The Comparison of Participation in School-Aged Cerebral Palsy Children and Normal Peers: A Preliminary Study
}

\author{
Afsoon Hassani Mehraban, ${ }^{1}$ Madineh Hasani, ${ }^{2,}{ }^{,}$and Malek Amini ${ }^{1}$ \\ ${ }^{1}$ Department of Occupational Therapy and Rehabilitation Research Center, School of Rehabilitation Sciences, Iran University of Medical Sciences, Tehran, IR Iran \\ ${ }^{2}$ Tabriz University of Medical Sciences, Tabriz, IR Iran \\ "Corresponding author: Madineh Hasani, Tabriz University of Medical Sciences, Tabriz, IR Iran. E-mail: madinehh@gmail.com
}

Received 2016 January 05; Accepted 2016 January 26.

\begin{abstract}
Background: Participation in daily activities during childhood is an important aspect for health and social development. Objectives: This study was designed to investigate the participation of children with cerebral palsy aged 8 to 14 years, and their normal peers.

Patients and Methods: In this cross-sectional study, 30 children with cerebral palsy, and 30 normal children were selected via the non-probability convenience sampling. Their participation was evaluated with children's assessment of participation and enjoyment (CAPE) through interviews.

Results: Significant differences were found between the means of the two groups regarding the diversity, intensity, overall participation $(\mathrm{P}=0.000)$ and all types of the activities except the recreational activities. The children with cerebral palsy took part in the skill-based activities and overall activities individually compared to the normal peers. The children with cerebral palsy, in comparison with their normal peers, often performed most of the activities inside the house. The main effect of gender and the interaction between gender and groups were not statistically significant in any of the variables of the CAPE test.

Conclusions: Physical disability can influence the children's daily activities and socialization. Understanding the participation of physically disabled children can help health care professionals in designing and introducing appropriate treatment according to their needs.
\end{abstract}

Keywords: Social Participation, Cerebral Palsy, Physical Activity, Children, Disability

\section{Background}

Participation in daily activities in childhood is essential for the health of all children regardless of their abilities or disabilities (1). According to international classification of functioning, disability and health (ICF), world health organization, defines participation as involvement in a life situation (2). This involvement in purposeful activities enables the child to gain confidence, develop skills, and create a sense of competence. It is also necessary for the physical, psychological, and emotional health $(1,3,4)$. Children's participation in the activities outside school can provide opportunities for skill acquisition and role competency, and minimize the likelihood of the emotional and behavioral problems. Various studies indicate that children with disabilities experience greater participation restrictions (5-7), low variability, more in-home activities, less social and physical activity involvement are characteristics of participation of disabled children (8-12). The children's ability in movement, communication, problem solving, and socialization is influenced by sensory-motor problems which reduce the probability of their participa- tion in leisure activities (13). Cerebral palsy (CP) as the most common neurological disorder in children (14) is associated with an upper motor neuron lesion occurring in the immature brain. Of the patients with CP, 80\% - 90\% have muscle and soft tissue contracture, bony deformities, and as a result of these, increasing limitations in activity, function, and participation (15). Engel-Yeger et al. (2009) reported that normal children participated more than children with cerebral palsy; however, in some areas, the participation in activities at home for children with cerebral palsy were greater than for normal peers (16). In order to understand variations of the children's participation, it is required to consider prerequisites of the participation, family priorities, and the key points such as "how", "where" and "with whom "the activities are performed. Studies demonstrate that personal factors (e.g., age and gender) and environmental factors (such as family situation, culture, and the living place) can have impact on the children's participation $(1,17)$. Different social contexts and cultural expectations have much bearing on whatever they learn and carry out, and can bring about different participation patterns $(4,18)$. Yan et al. (2004) showed that the 
motivation of Chinese children and adolescents in participating in physical activities differed from that of American children and adolescents (19). Engel-Yeger et al. (2007) also reported that culture can have a significant effect on the levels of children's participation in the community (20). Enormous differences and variations in time used could be observed among different countries. These differences can also affect the level of children's involvement in leisure activities. Consequently, probably participation varies from one country to another or even from one culture to another (7). All of these studies are conducted in special cultures and countries (8-16); no study on participation of the children with cerebral palsy has been performed in Iran.

\section{Objectives}

Given that the ultimate purpose of the occupational therapy's intervention for the children with disabilities is to enable them to participate in the childhood activities, the purpose of this preliminary study was to investigate the participation of the children with cerebral palsy (CP) in out of school activities, and to compare it with normal peers.

\section{Patients and Methods}

\subsection{Participants}

In the present study, participants were 30 children with cerebral palsy aged 8 to 14 years from special schools for physical disabled children through convenience sampling method and 30 children of the same age from the regular schools. Both groups were matched regarding their gender and age. Inclusion criteria for selection of participants were: 1 , having normal or borderline intelligence quotient based on school documents; 2 , being without any co-morbidity including pervasive developmental, learning, and psychiatric disorders; 3 , understanding the persian language and concepts by all normal peers and cerebral palsy children; 4, having independent ambulation with or without assistive devices.

\subsection{Procedures}

This study was a comparative cross-sectional research. In this study, the children's participation was measured using the CAPE test. This test was developed to evaluate the participation of the children with disabilities or without disabilities aged 6 to 21 years in daily activities out of school. The children could participate in the study if their parents filled out the informed consent form. Regarding the children with cerebral palsy (CP group), the therapist initially determined the child's level gross motor function classification system (GMFCS) via observation. The procedure of data collection was done through completing CAPE forms and cards during interviews with children by therapists. On each card there was a picture of the activity accompanied by a phrase or word which described that activity. Moreover, therapists used rest time during interview if necessary. The child was asked to rate the way she/he had performed the activity in the past 4 months on a 7-point scale (from 1 to 7 ), and the enjoyment of doing it on a 5point scale (from 1 to 5). Accordingly, five types of scoring were obtained from the test:

1. The diversity of participation (diversity): Does the child perform the activity or not?

2. The intensity of participation (intensity): how many times does the child do the activity?

3. The enjoyment of participation (enjoyment): how much does the child enjoy doing the activity?

4. The role of others in participation (with whom): with whom does the child often do the activity?

5. The place of Participation (where): where does the child often do the activity?

This test consists of 55 activities, and based on the principal component analysis, the priorities of the children were divided into 5 types of activities including recreational, physical, social, skill-based, and self-help activities. The reliability and validity of this test were evaluated for the first time in Canada in by King et al. (21) who conducted the study on 427 children with physical disabilities. The estimated reliability for the CAPE test in terms of the diversity of participation was 0.75 to 0.93 , and the validity was also checked. In Iran, the content and face validities of this test were also approved qualitatively in expert panel sessions in occupational therapy department of Iran University of Medical Sciences.

\subsection{Statistical Analyses}

For data analysis, SPSS 17 software was utilized. The descriptive statistics (mean, standard seviation, etc.) were used to describe the level of children's participation and enjoyment for all of the items in the CAPE test. A twoway ANOVA was conducted to explore the interaction of gender (boys and girls) and groups (cerebral palsy group [CP group] and normal peer group [NP group]); moreover, the Bonferroni adjustment was used as the post hoc analysis for the multiple comparisons between groups and genders.

\section{Results}

The levels of the participation of 30 school-age children with cerebral palsy, and 30 normal children of the same 
age were examined. Demographic characteristics of the children with cerebral palsy and their normal peers are shown in Table 1.

Out of 55 activities, the average number of activities (the diversity of participation) done by the $\mathrm{CP}$ group and the NP group was 23 and 32 activities respectively. The results of the ANOVA indicated that regarding the diversity and intensity of participation, the main effect of groups was significant for all measures except the recreational activities, and the size effect values were from moderate to strong (Table 2). In comparison with the NP group, the children with cerebral palsy (the $\mathrm{CP}$ group) participated in the skill and overall activities individually (with whom dimension) with the moderate to strong effect size values (Table 2). However, no significant difference was observed between the two groups regarding other types of activities. The children with cerebral palsy, in comparison with normal children, performed most of the activities inside the house except the recreational and social activities, and there was no significant difference between the two groups regarding the place of participation (where dimension). The main effect of gender and interaction of genders and groups was not significant in none of the test parameters (Table 2).

The results of the post hoc analysis for multiple comparisons between groups (the CP and NP groups) and between genders (the boys and girls) are shown in Figure 1. Regarding the variables of the overall diversity, intensity, and place of participation, a significant difference was seen between the boys' and girls' participation in the CP and NP groups; however, regarding the role of others in the participation, there was no significant difference in the boys' and girls' participation in the CP and NP groups. Furthermore, the boys' and girls' participation in all parameters in the $\mathrm{CP}$ and NP groups was compared and no significant difference was found (Figure 1).

\section{Discussion}

Participation in daily activities is essential for the development of the physical, emotional, social-psychological skills, and is also deemed as the major goal of rehabilitation after brain damage. Participation patterns are entirely dependent on the culture; therefore, perhaps it is not sensible to generalize the results of the studies undertaken in one culture to other cultures. This study, as a pilot study, was conducted to assess the children's participation in activities outside school in Tehran. The mean of the overall diversity of participation for the children with cerebral palsy (23.066) was greater than that reported on EngelYeger (2009) (16) and Longo et al. (2013) (22) studies undertaken in Israel and Spain. The differences in the diversity
Table 1. Descriptive Statistics of CP and NP Groups

\begin{tabular}{|c|c|c|}
\hline Variables & $\begin{array}{c}\text { Frequency of CP } \\
\text { Group }\end{array}$ & $\begin{array}{c}\text { Frequency of NP } \\
\text { Group }\end{array}$ \\
\hline \multicolumn{3}{|l|}{ Gender } \\
\hline Girls & 50 & 50 \\
\hline Boys & 50 & 50 \\
\hline \multicolumn{3}{|l|}{ Educational degree } \\
\hline \multicolumn{3}{|l|}{ Primary school } \\
\hline First grade $^{\mathrm{a}}$ & 13.9 & 0 \\
\hline Second grade ${ }^{a}$ & 16.7 & 0 \\
\hline Third grade $^{a}$ & 2.8 & 10 \\
\hline Fourth grade $^{\mathrm{a}}$ & 13.9 & 13.3 \\
\hline Fifth grade ${ }^{a}$ & 22.2 & 20 \\
\hline \multicolumn{3}{|l|}{ Guidance school } \\
\hline First grade ${ }^{b}$ & 11.1 & 16.7 \\
\hline Second grade ${ }^{b}$ & 2.8 & 20 \\
\hline Third grade $\mathrm{e}^{\mathrm{b}}$ & 0 & 20 \\
\hline
\end{tabular}

Level GMFCS

\begin{tabular}{|cc|}
\hline Level 1 & 23,3 \\
\hline Level 2 & 26,7 \\
\hline Level 3 & 30 \\
\hline Level 4 & 13,3 \\
\hline Level 5 & 6,7 \\
\hline
\end{tabular}

\section{Vision problems}

No problem $\quad 46.7$

Strabismus $\quad 16.7$

Low 33.3

impairment

(using glasses)

Unknown

3.3

Hearing problems

No problem 90

Deaf 0

Low 10

impairment $^{c}$

Speech problems

$\begin{array}{ll}\text { No problem } & 46.7\end{array}$

No speech $\quad 6.7$

Low 40

impairment

Unknown

6.7

Abbreviation: GMFCS, gross motor function classification system.

${ }^{\text {a }}$ Primary school.

${ }^{\mathrm{b}}$ Guidance school.

${ }^{\mathrm{c}}$ Requiring the use of the hearing aids. 
Table 2. The Results of the ANOVA for the Two Groups (the CP and NP Groups) and Gender (the Males and Females) in Terms of the CAPE Test's Variables

\begin{tabular}{|c|c|c|c|c|c|c|}
\hline \multirow[t]{2}{*}{ CAPE Variable } & \multicolumn{2}{|c|}{ Group } & \multicolumn{2}{|c|}{ Gender } & \multicolumn{2}{|c|}{ Group $\times$ Gender } \\
\hline & $\mathbf{F}(\mathbf{1})$ & $\eta_{\rho}^{2}$ & $\mathbf{F}(\mathbf{1})$ & $\eta_{\rho}^{2}$ & $\mathbf{F}(\mathbf{1})$ & $\eta_{\rho}^{2}$ \\
\hline \multicolumn{7}{|l|}{ Overall } \\
\hline Diversity & $29.344^{c}$ & 0.344 & 0.132 & 0.002 & 0.88 & 0.015 \\
\hline Intensity & $26.297^{\mathrm{C}}$ & 0.32 & 0.108 & 0.002 & 1.121 & 0.02 \\
\hline Whom & $5.202^{\mathrm{a}}$ & 0.085 & 0.134 & 0.002 & 0.339 & 0.006 \\
\hline Where & $27.022^{\mathrm{C}}$ & 0.325 & 0.162 & 0.003 & 1.888 & 0.015 \\
\hline \multicolumn{7}{|c|}{ Recreational activities } \\
\hline Diversity & 1.514 & 0.026 & 0.000 & 0.000 & 1.831 & 0.032 \\
\hline Intensity & 1.312 & 0.023 & 0.195 & 0.003 & 0.003 & 0.000 \\
\hline Whom & 0.483 & 0.009 & 1.552 & 0.027 & 0.733 & 0.013 \\
\hline Where & 3.999 & 0.062 & 0.676 & 0.012 & 0.004 & 0.000 \\
\hline \multicolumn{7}{|l|}{ Social activities } \\
\hline Diversity & $9.645^{\mathrm{b}}$ & 0.147 & 0.052 & 0.001 & 0.143 & 0.003 \\
\hline Intensity & $7.431^{\mathrm{b}}$ & 0.117 & 0.002 & 0.000 & 0.099 & 0.002 \\
\hline Whom & 0.676 & 0.012 & 0.025 & 0.004 & 0.131 & 0.002 \\
\hline Where & 3.424 & .058 & 3.032 & 0.051 & 0.891 & 0.016 \\
\hline \multicolumn{7}{|c|}{ Active physical activities } \\
\hline Diversity & $45.06^{\mathrm{C}}$ & 0.446 & 2.611 & 0.045 & 1.87 & 0.032 \\
\hline Intensity & $16.521^{\mathrm{c}}$ & 0.228 & 0.103 & 0.002 & 0.146 & 0.003 \\
\hline Whom & 3.627 & 0.061 & 0.192 & 0.003 & 0.152 & 0.003 \\
\hline Where & $24.779^{c}$ & 0.307 & 0.244 & 0.004 & 2.882 & 0.049 \\
\hline \multicolumn{7}{|c|}{ Skill-based activities } \\
\hline Diversity & $21.27^{c}$ & 0.275 & 0.01 & 0.000 & 0.472 & 0.008 \\
\hline Intensity & $23.576^{\mathrm{C}}$ & 0.296 & 0.139 & 0.002 & 0.427 & 0.008 \\
\hline Whom & $22.869^{c}$ & 0.29 & 0.01 & 0.000 & 1.467 & 0.026 \\
\hline Where & $14.369^{\mathrm{c}}$ & 0.204 & 0.024 & 0.000 & 1.423 & 0.025 \\
\hline \multicolumn{7}{|c|}{ Self-improvement activities } \\
\hline Diversity & $9.526^{c}$ & 0.145 & 1.058 & 0.019 & 0.000 & 0.000 \\
\hline Intensity & $16.469^{c}$ & 0.227 & 0.008 & 0.000 & 0.014 & 0.000 \\
\hline Whom & 0.038 & 0.001 & 3.298 & 0.056 & 1.025 & 0.018 \\
\hline Where & $7.355^{\mathrm{b}}$ & 0.116 & 0.151 & 0.003 & 2.651 & 0.045 \\
\hline
\end{tabular}

Abbreviation: CAPE, Children's assessment of participation and enjoyment.

${ }^{\mathrm{a}} \mathrm{P}<0.05$.

${ }^{\mathrm{b}} \mathrm{P}<0.01$.

${ }^{\mathrm{C}} \mathrm{P}<0.001$.

of participation were found to be significant between the two groups in all measures except for the recreational activities. This finding supports the results observed in the comparative study of Engel-Yeger (2009) (16) on the children with cerebral palsy and their normal peers all aged 12 to 16 years. It was also aligned with the finding of Brown and Gordon (1987) (9) study in children with physical disabilities. However, in terms of skill activities, the finding was not in line with the findings of Engel-Yeger (2009) (20) study. Regarding the intensity of participation, the differences between the CP and NP groups in all types of activities, except for recreational activities, were also statistically 

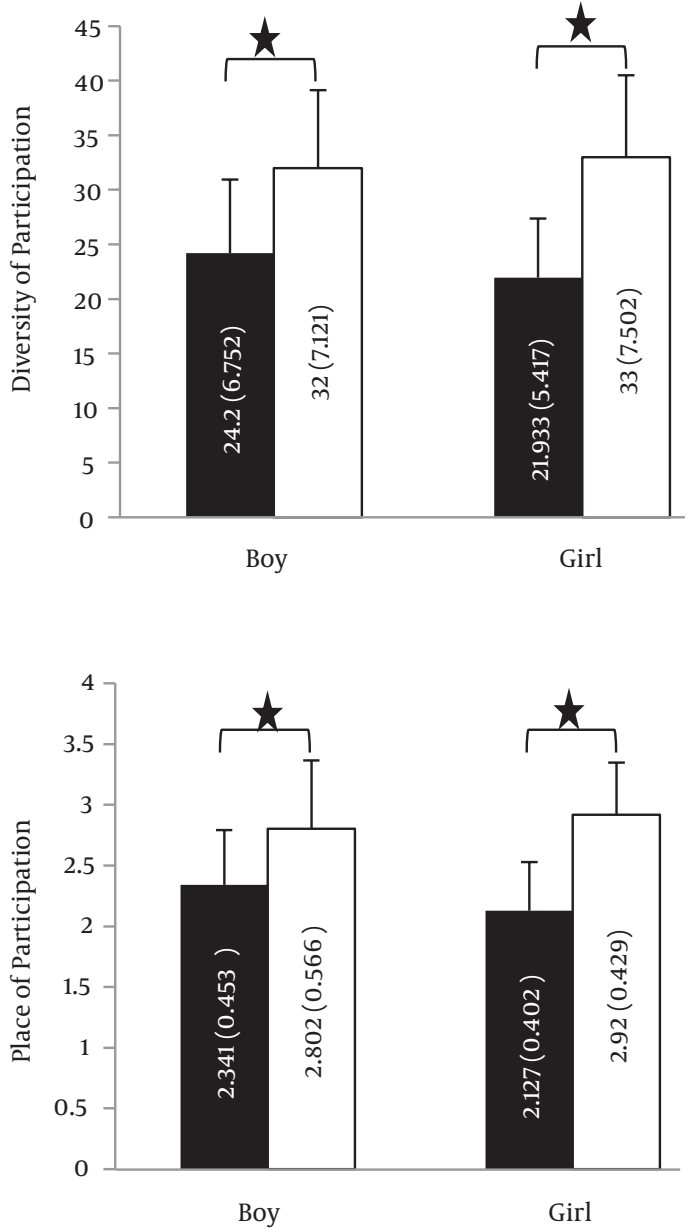
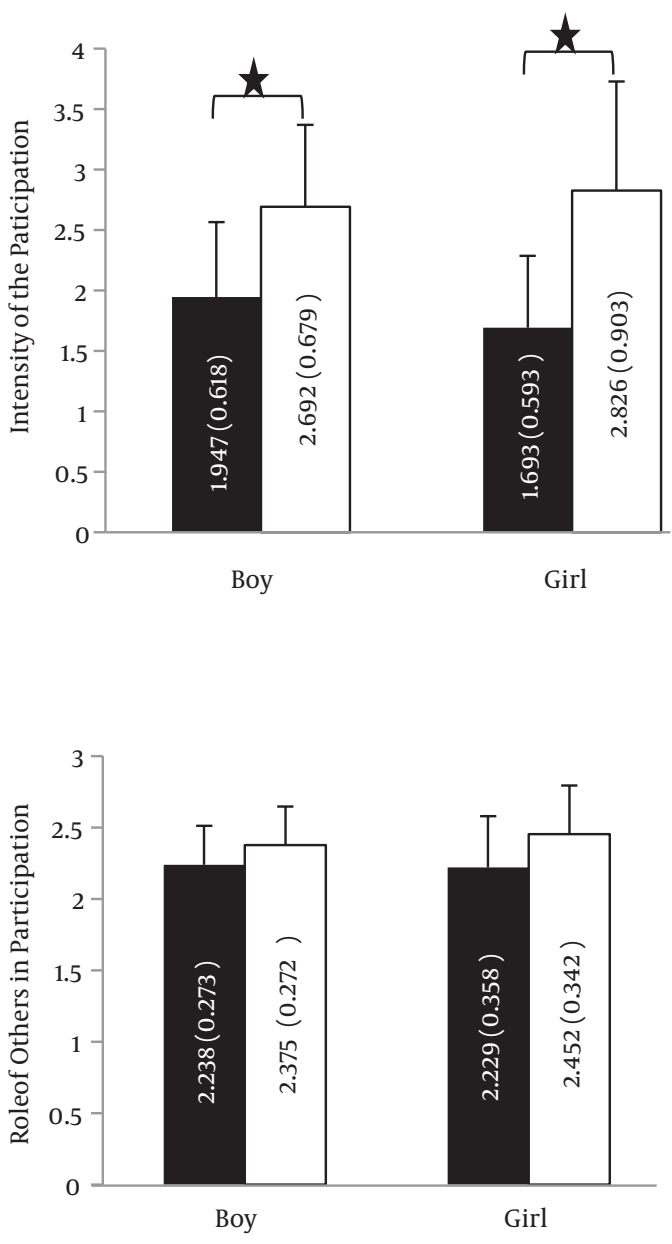

It is in the two groups according to the diversity, intensity, place, and enjoyment of participation and the role of others in participation. The results of the multiple comparisons that were significantly different. $\mathrm{P}<0.025$ are shown with an asterisk.

significant, which corresponds with the results of the previous studies $(7,16)$. Palisano et al. (2011) (23) suggest that in children with cerebral palsy, greater physical activity is associated with a higher intensity of participation (23).The low intensity of participation influences the body fitness, the skill development, the probability of acceptance by their normal peers, the development of the friendly relationships, and the feelings about oneself (7). The children with cerebral palsy had the most diversity and intensity of participation in the recreational activities and the least diversity and intensity of participation in the skill activity. Investigating the participation of the children with cerebral palsy, Majnemer et al. (2008) (13) and Longo et al. (2013) (22) concluded that the participation of the children with cerebral palsy in the physical and skill-based activities was less than that in other leisure and recreational activities
$(13,22)$. Law et al. (2006) (8) study in children with physical disabilities, aged 8 to 14 years, and many other studies also found similar results $(7,8,24)$. Due to the fact that a majority of physical and skill-based activities is required to be done outside and needs physical abilities, the children with cerebral palsy seem to have less opportunity to participate in such activities especially due to their physical as well as access problems. Their normal peers also indicated the most diversity of participation in recreational activities and the least diversity in skill activities; however, the normal peers had the most intensity of participation in the self-help activities and the least intensity in the skill activities. Some of the reasons of the low intensity of participation of the children with cerebral palsy can be found in the problems related to handling and transfer by their parents and the cost of these children's participation in 
the leisure activities, while this money could be expended on their treatment. In comparison with the normal children, the children with cerebral palsy preferred to perform the skill and overall activities by themselves, which can be owing to the fact that their normal peers would rather cooperate with their friends in performing these activities; while the physical restrictions of the children with CP may impede them from doing various activities in different environments. Therefore, they perform the activities in the environments which are adapted based on their disabilities such as home and schools $(8,16)$. Nonetheless, considering this aspect (whom dimension), no significant difference was found between the two groups regarding the recreational, actively physical, social, and self-help activities. Participating in these activities is of paramount importance for the children with cerebral palsy, which means that they recognize themselves as part of the family and society; otherwise, they, in comparison with their normal peers, participate less in the activities outside school. This can be due to the fact that the children with cerebral palsy would rather perform the activities at home where parents can assist them more. On the contrary, the peers without cerebral palsy are more independent and are able to spend part of their time outside the house. Children with disabilities and their families encounter the contradictions of the development of the emotional independence and an independent identity, while these children are still physically dependent on their parents or caregivers (25).

The main effect of gender and that of the interaction of groups and genders were not significant in any of the test parameters, which is in line with the results reported in some previous studies. However, considering the diversity of participation, the findings support the results of King et al. (2006) (21) study in which they observed that the diversity of participation was only greater in the selfhelp activities for the girls with physical disabilities than for physically disabled boys. According to the results of various studies, it seems that gender and culture can affect the type of the activities selected by them and the activity pattern. Gender is deemed as an important factor in the participation, especially in performing the leisure activities $(26,27)$. Investigating normal children in two different cultures, Engel-Yeger et al. (2007) concluded that there was a significant interaction between culture and gender (20).

Participation in out-of-school time plays an important role in the health, welfare, and development of children. The participation of the children with physical disabilities in daily activities is an influential factor in gaining independence in adulthood (28). Participation as a key purpose of rehabilitation programs has grabbed enormous attention with the intention of helping children and families in coping with the challenges they face (29). Levels of partic- ipation in the life roles may be modified due to the functional limitations and environmental and personal factors (30). The main goal of rehabilitation for school-age children with cerebral palsy is to enhance independence in self- care, mobility, and productivity (30). Increasing participation can be considered as the ultimate goal of rehabilitation; hence, measuring the level of participation is essential for evaluating the effectiveness of rehabilitation programs (31).

Based on the results, it can be declared that the cerebral palsy can affect the diversity and intensity of the children's participation. Regarding the great importance of participation in the purposeful childhood activities and its impact on health and growth of children, the understanding of the participation patterns of the children with cerebral palsy and without disabilities can pave the way for the occupational therapists and families to design activities and treatments tailored to the needs of the children and promote their health and participation.

\section{Acknowledgments}

This article is part of an approved project in Iran University of Medical Sciences. All authors appreciate cooperation of ministry for education.

\section{References}

1. Rodger S, Ziviani J. Occupational therapy with children. 55. ;2006.

2. World Health Organization . International classification of functioning, disability and health: ICF. World Health Organization; 2001.

3. King G, Lawm M, King S, Rosenbaum P, Kertoy MK, Young NL. A Conceptual Model of the Factors Affecting the Recreation and Leisure Participation of Children with Disabilities. Phys Occu J. 2009;23(1):63-90. doi:10.1080/J006v23n01_05.

4. Law M. Participation in the Occupations of Everyday Life. Am J Occup Ther. 2002;56(6):640-9. doi:10.5014/ajot.56.6.640.

5. Ehrmann LC, Aeschleman SR, Svanum S. Parental reports of community activity patterns: A comparison between young children with disabilities and their nondisabled peers. Red Develop Disab. 1995;16(4):331-43. doi: 10.1016/0891-4222(95)00017-h.

6. Scehenker R, Coster WJ, Parush S. Neuroimpairments, activity performance, and participation in children with cerebral palsy mainstreamed in elementary schools. Develop Med Child Neurol. 2007;47(12):808-14. doi:10.1111/j.1469-8749.2005.tb01085.x.

7. Imms C, Reilly S, Carlin J, Dodd K. Diversity of participation in children with cerebral palsy. Develop Med Child Neurol. 2008;50(5):363-9. doi: 10.1111/j.1469-8749.2008.02051.x.

8. Law M, King G, King S, Kertoy M, Hurley P, Rosenbaum P, et al. Patterns of participation in recreational and leisure activities among children with complex physical disabilities. Dev Med Child Neurol. 2006;48(5):337-42. doi: 10.1017/S0012162206000740. [PubMed: 16608540].

9. Brown M, Gordon WA. Impact of impairment on activity patterns of children. Arch Phys Med Rehabil. 1987;68(12):828-32. [PubMed: 2962558]. 
10. Margalit M. Leisure activities of learning disabled children as a reflection of their passive life style and prolonged dependency. Child Psychiat Hum D. 1984;15(2):133-41. doi: 10.1007/bfo0706169.

11. Law M, Finkelman S, Hurley P, Rosenbaum P, King S, King G, et al. Par ticipation of children with physical disabilities: relationships with diagnosis, physical function, and demographic variables. Scan JOccup Ther. 2009;11(4):156-62. doi:10.1080/11038120410020755.

12. Longrnuir PE, Bar-Or O. Factors influencing the physical activity levels of youths with physical and sensory disabilities. APAQ. 2000;17(40):40-53.

13. Majnemer A, Shevell M, Law M, Birnbaum R, Chilingaryan G, Rosenbaum $\mathrm{P}$, et al. Participation and enjoyment of leisure activities in school-aged children with cerebral palsy. Dev Med Child Neurol. 2008;50(10):751-8. doi: 10.1111/j.1469-8749.2008.03068.x. [PubMed: 18834388].

14. Cans C. Surveillance of cerebral palsy in Europe: a collaboration of cerebral palsy surveys and registers. Dev Med Child Neurol. 2007;42(12):816-24. doi:10.1111/j.1469-8749.2000.tb00695.x.

15. Morrell DS, Pearson JM, Sauser DD. Progressive Bone and Joint Abnor malities of the Spine and Lower Extremities in Cerebral Palsy 1. Radiographics. 2002;22(2):257-68.

16. Engel-Yeger B, Jarus T, Anaby D, Law M. Differences in patterns of participation between youths with cerebral palsy and typically developing peers. Am J Occup Ther. 2009;63(1):96-104. [PubMed: 19192732].

17. Hammal D, Jarvis SN, Colver AF. Participation of children with cerebral palsy is influenced by where they live. Dev Med Child Neurol. 2004;46(5):292-8. [PubMed: 15132258].

18. Rodger S, Ziviani J. Children's participation beyond the school grounds. Blackwel: Oxford; 2006.

19. Yan JH, McCullagh P. Cultural influence on youth's motivation of participation in physical activity. J Sport Behav. 2004;27(4):378.

20. Engel-Yeger B, Jarus T, Law M. Impact of culture on children's community participation in Israel. Am J Occup Ther. 2007;61(4):421-8. [PubMed: 17685175].

21. King G, Tucker MA, Baldwin P, Lowry K, LaPorta J, Martens L. Predictors of the leisure and recreation participation of children with physical disabilities: a structural equation modeling analysis. Children's Health Care. 2006;35(2):24-9. [PubMed: 12216367].
22. Longo E, Badia M, Orgaz BM. Patterns and predictors of participation in leisure activities outside of school in children and adolescents with Cerebral Palsy. Res Dev Disabil. 2013;34(1):266-75. doi: 10.1016/j.ridd.2012.08.017. [PubMed: 22989575].

23. Palisano RJ, Orlin M, Chiarello LA, Oeffinger D, Polansky M, Maggs $\mathrm{J}$, et al. Determinants of intensity of participation in leisure and recreational activities by youth with cerebral palsy. Arch Phys Med Rehabil. 2011;92(9):1468-76. doi: 10.1016/j.apmr.2011.04.007. [PubMed: 21878219].

24. Orlin MN, Palisano RJ, Chiarello LA, Kang LJ, Polansky M, Almasri N, et al. Participation in home, extracurricular, and community activities among children and young people with cerebral palsy. Dev Med Child Neurol. 2010;52(2):160-6. doi: 10.1111/j.1469-8749.2009.03363.x. [PubMed: 19549198].

25. Rogers SL. Common conditions that influence children's participation. Occupational therapy for children. 2005;5

26. Freysinger VI, Alessio H, Mehdizadeh S. Re-Examining the Morale. Activities, Adaptation Aging. 1993;17(4):25-41.doi:10.1300/J016v17n04_04.

27. Garton AF, Pratt C. Leisure activities of adolescent school students: predictors of participation and interest. Journal of Adolescence. 1991;14(3):305-21. doi: 10.1016/0140-1971(91)90023-k.

28. Blum RW, Resnick MD, Nelson R, St Germaine A. Family and peer issues among adolescents with spina bifida and cerebral palsy. Pediatrics. 1991;88(2):280-5. [PubMed: 1861926].

29. King G, Tucker MA, Baldwin P, Lowry K, LaPorta J, Martens L. A life needs model of pediatric service delivery: services to support community participation and quality of life for children and youth with disabilities. Phys Occup Ther Pediatr. 2002;22(2):53-77. [PubMed: 12216367].

30. Majnemer A, Shikako-Thomas K, Chokron N, Law M, Shevell M, Chilingaryan $\mathrm{G}$, et al. Leisure activity preferences for 6- to 12-year-old children with cerebral palsy. Dev Med Child Neurol. 2010;52(2):167-73. doi: 10.1111/j.1469-8749.2009.03393.x. [PubMed: 20002127].

31. Sakzewski L, Boyd R, Ziviani J. Clinimetric properties of participation measures for 5- to 13-year-old children with cerebral palsy: a systematic review. Dev Med Child Neurol. 2007;49(3):232-40. doi: 10.1111/j.14698749.2007.00232.x. [PubMed: 17355482]. 